Original Research Paper

\title{
About Glassy Amorphous Metal Injection
}

\author{
${ }^{1}$ Raffaella Aversa, ${ }^{2}$ Relly Victoria Petrescu, \\ ${ }^{1}$ Antonio Apicella, ${ }^{3}$ Samuel Kozaitis, ${ }^{4}$ Taher Abu-Lebdeh, \\ ${ }^{5}$ Bilal Akash and ${ }^{2}$ Florian Ion Tiberiu Petrescu \\ ${ }^{1}$ Advanced Materials Lab, Second University of Naples, Naples, Italy \\ ${ }^{2}$ IFToMM, ARoTMM, Bucharest Polytechnic University, Bucharest, Romania \\ ${ }^{3}$ Florida Institute of Technology, USA \\ ${ }^{4}$ North Carolina A and T State University, USA \\ ${ }^{5}$ Dean of School of Graduate Studies and Research, American University of Ras Al Khaimah, UAE
}

\author{
Article history \\ Received: $12-12-2017$ \\ Revised: 16-01-2018 \\ Accepted: 22-01-2018 \\ Corresponding Author: \\ Florian Ion Tiberiu Petrescu \\ IFToMM, ARoTMM, \\ Bucharest Polytechnic \\ University, Bucharest, \\ Romania \\ Email: fitpetrescu@gmail.com
}

Abstract: The paper aims to present studies on the melt flow, melting and rheology of melting in a super-cooled metastable liquid metal, which is injection molded, of the $\mathrm{Zr}_{44}-\mathrm{Ti}_{11}-\mathrm{Cu}_{10}-\mathrm{Ni}_{10}-\mathrm{Be}_{25}$ alloy, which can induce selective crystallization. In this process, high Be-velocities were observed, $\mathrm{Cu}$ and $\mathrm{Ni}$ atoms that crystallized differently in superficial bulk metallic bulk liquids. It wants to highlight and analyze the result of the morphological behavior of microscopic observation regarding Glass Bulk Metallic (BMG) with the composition of a commercial liquid metal alloy (LM001B). One specifies that the injection molded plate was supplied to us by Liquid Metals Technologies Inc., $\mathrm{Ca}$, USA and was manufactured using an Engel injection molding machine operating at $1050-1100^{\circ} \mathrm{C}$. The sample that was observed was then cut with a jet of water. FEI Scios Dual-Beam performed microscopic observation. In a cross-section, the presence of crystalline phases can be observed on short-range command. It is also investigated the presence of short-range command groups, their distribution and the effect they can have on the behaviors and properties of alloys. We can now talk about a new material revolution by putting in bulk metallic glasses, Inside Bulk Metallic, (BMGs). It's about metals that are very different from each other, but they can still be combined with the help of intense heat and melted together to produce a beautifully colored and hot liquid. When this liquid is cooled very quickly (fast enough), the metal atoms manage to retain the liquid in a totally random manner, thus forming an amorphous alloy. Glasses made of this amorphous material are very scratch-resistant, BMG material being a plastic, amorphous, but also elastic, but very resistant. You can even speak one of the most powerful materials known today! The weight ratio of BMG can usually be twice as high as that of titanium, magnesium or aluminum. The hardness of the BMG type material is typically a Vickers hardness of more than 500 , which is about twice the hardness of most quality stainless steels and titanium and at least four times the hardness of the aluminum and magnesium. BMGs can be three times more elastic or more resistant than virtually all known crystal metal alloys. Some BMGs are highly corrosion-resistant, with alloys containing elements such as beryllium or niobium that tend to be very corrosive. In general, erosion resistance is remarkable in all these BMGs.

Keywords: Rheology, Bulk Glass Metals, Chemo Rheological Model, Segregation, Cold Crystallization
(C) 2018 Raffaella Aversa, Relly Victoria Petrescu, Antonio Apicella, Samuel Kozaitis, Taher Abu-Lebdeh, Bilal Akash and Florian Ion Tiberiu Petrescu. This open access article is distributed under a Creative Commons Attribution (CC-BY) 3.0 


\section{Introduction}

Today one can talk about a new material revolution by putting in bulk metallic glasses, Inside Bulk Metallic, (BMGs).

It's about metals that are very different from each other, but they can still be combined with the help of intense heat and melted together to produce a beautifully colored and hot liquid. When this liquid is cooled very quickly (fast enough), the metal atoms manage to retain the liquid in a totally random manner, thus forming an amorphous alloy. Glasses made with this amorphous material are very scratch-resistant, BMG material being a plastic, amorphous, but also elastic, but very resistant. You can even speak one of the most powerful materials known today!

The weight ratio of BMG can usually be twice as high as that of titanium, magnesium or aluminum.

The hardness of the BMG type material is typically a Vickers hardness of more than 500, which is about twice the hardness of most quality stainless steels and titanium and at least four times the hardness of the aluminum and magnesium (Busch, 2000).

BMGs can be three times more elastic or more resistant than virtually all known crystal metal alloys.

Some BMGs are highly corrosion-resistant, with alloys containing elements such as beryllium or niobium that tend to be very corrosive. In general, erosion resistance is remarkable in all these BMGs.

The manufacturing of BMG components requires such plastics, their ability to be processed using a hybrid injection molding and casting mold, casting them resulting in many complicated shapes with high dimensional tolerance and different characteristics.

Thanks to this ease of manufacture, their processing and their surface, they involve very little modification operations. BMGs can also be deformed by forging - such as operations under control atmospheric and temperature.

The paper aims to present studies on the melt flow, melting and rheology of melting in a super-cooled metastable liquid metal, which is injection molded, of the $\mathrm{Zr}_{44}-\mathrm{Ti}_{11}-\mathrm{Cu}_{10}-\mathrm{Ni}_{10}-\mathrm{Be}_{25}$ alloy, which can induce selective crystallization. In this process, high Bevelocities were observed, $\mathrm{Cu}$ and $\mathrm{Ni}$ atoms that crystallized differently in superficial bulk metallic bulk liquids. Want to highlight and analyze the result of the morphological behavior of microscopic observation regarding Glass Bulk Metallic (BMG) with the composition of a commercial liquid metal alloy (LM001B). We specify that the injection molded plate was supplied to us by Liquid Metals Technologies Inc., $\mathrm{Ca}$, USA and was manufactured using an Engel injection molding machine operating at $1050-1100^{\circ} \mathrm{C}$. The sample that was observed was then cut with a jet of water. FEI Scios Dual-Beam performed microscopic observation. In a cross-section, the presence of crystalline phases can be observed on short-range command. It is also investigated the presence of short-range command groups, their distribution and the effect they can have on the behaviors and properties of alloys.

Metal Bulk Glasses (BMG), also called bulk amorphous alloys, is a category of advanced materials with a disordered atomic structure. Their unique microstructure often attributes remarkable properties (Huang et al., 2016) to the manufacturers.

Scientists and researchers in recent years have studied Zr-based bulk materials for their superior Glass Forming Ability (GFA) and their mechanical properties. Their features range from high mechanical strength, high breaking strength, superior elastic limit to good and accurate deformability, good ductility, low thermal expansion coefficient and excellent corrosion/wear resistance.

Slag-based multiple alloy microspheres have a superior Glass Forming Capacity (GFA) and can be produced in parts of a thickness greater than a few centimeters by conventional melting and casting techniques (Liu et al., 2002).

Among other things, BMG's advantage is a net cost that provides the opportunity to produce more personalized tools for specific applications across a wide range of industries.

To produce these melted aluminum bottles, critical cooling rates $\left(>103^{\circ} \mathrm{K} / \mathrm{s}\right)$ are required, a rapid solidification technique can maintain liquid amorphous microstructure (Huang et al., 2016; Petrescu and Calautit, 2016a; 2016b; Aversa et al., 2017a; 2017b; 2017c; 2017d; 2017e; 2016a; 2016b; 2016c; 2016d; 2016e; 2016f; 2016g; 2016h; 2016i; 2016j; 2016k; 20161; 2016m; 2016n; 2016o; Mirsayar et al., 2017).

Microstructure is the most important feature of BMGs compared to conventional metals; common metals have a long-term crystalline structure; a periodic lattice where the patterns repeat. The microstructure of BMGs, on the contrary, does not present a long-term order but an amorphous structure of the short-range organization specific to glass materials (ceramics, polymers and metal); (Aversa et al., 2015; Aversa and Apicella, 2016; Petrescu et al., 2016a; 2016b; 2016c; 2016d; 2016e; 2015).

Here look at the result of a microscopic morphological observation made by Ion and electron microscopy.

\section{Materials and Procedures}

Differential scanning calorimetry using a Mettler Toledo DSC 822 method performed at a constant heating rate of $1 \mathrm{~K} / \mathrm{min}$ was used for the preliminary calorimetry analysis of our BMG alloy (Fig. 1).

The sample studied in this paper is a bulk metal bottle with a composition of $\mathrm{Zr}_{44} \mathrm{Ti}_{11} \mathrm{Cu}_{10} \mathrm{Ni}_{10} \mathrm{Be}_{25}$ (LM001B, Liquid Metals Technologies Inc., CA 
USA) of $3 \mathrm{~mm}$ thick and $13 \mathrm{~mm}$ in size on each side Fig. 2. The samples were cut from a plate made using an Engel injection molding machine operating at $1050-1100^{\circ} \mathrm{C}$. The sample was chosen because it had a surface defect obviously generated by the injection molding process. All cuts and sample preparations were obtained from the plate by jet cuttings. FEI Scios Dual-Beam was used for micro and nanocharacterization of the injection molded metallic glass structure. In particular, one investigates the surface defects and the presence of crystalline phases through the cross-section of the ion beam.

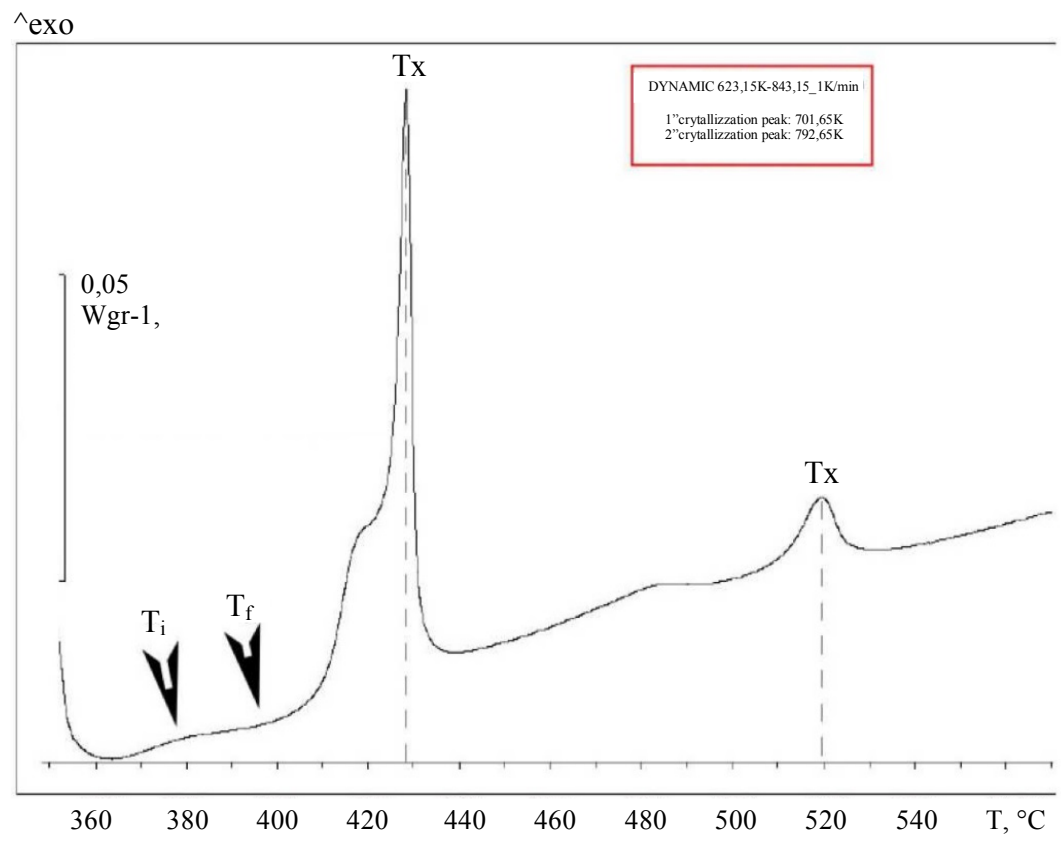

Fig. 1: DSC thermogram of $\mathrm{Zr}_{44}-\mathrm{Ti}_{11}-\mathrm{Cu}_{10}-\mathrm{Ni}_{10}-\mathrm{Be}_{25}$ metal glass Alloy: Heating rate $1^{\circ} \mathrm{K} / \mathrm{min}$

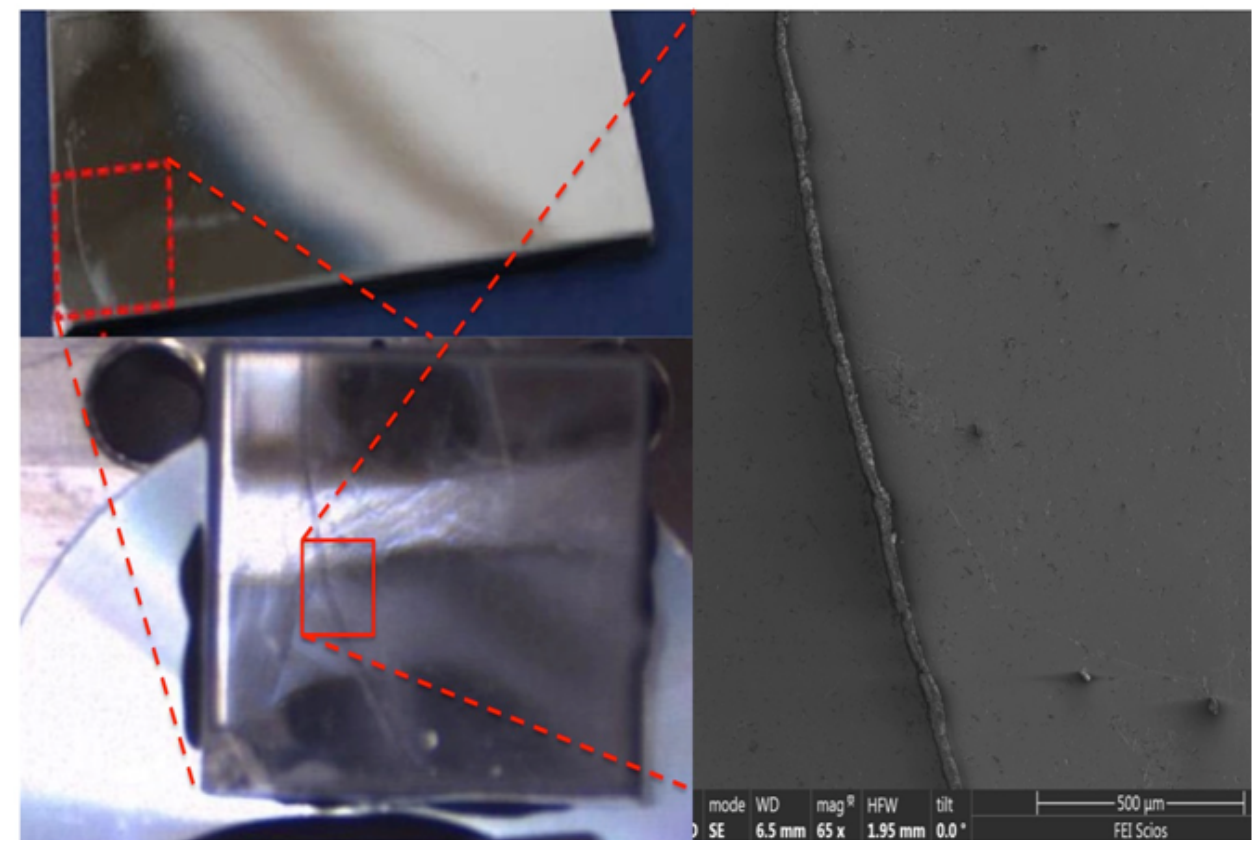

Fig. 2: Groove defect on the injection molded BMG slab analyzed using Dual Beam SE Microscopy 
Microscopic observation of the internal surface morphology and cross-sections at level of the surface defect were made by means of FEI Scios DualBeam using a Focused Ion Beam (FIB) for cross-sectioning and Scanning Electron Microscopy (SEM) for morphological analysis. The instrument was equipped with a chemical composition analysis detector Energy Dispersive Spectrometry (EDS).

\section{Results}

The DSC thermogram is shown in Fig. 1 with a heating section at 360 to $570^{\circ} \mathrm{C}$, a glass transition at 380$395^{\circ} \mathrm{C}$ and four exothermic crystallization peaks (Fig. 1) at $418,428,482$ and $520^{\circ} \mathrm{C}$ (Aversa and Apicella, 2016).
The first shoulder that occurs at $418^{\circ} \mathrm{C}$ may be caused by the precipitation of the icosahedral intermediate crystal phase (Murty and Hono, 2001) which, due to greater mobility and small size, is probably a rich phase. The second peak of crystallization $\left(428^{\circ} \mathrm{C}\right)$ was associated with the $\mathrm{Cu}-\mathrm{Ni}$ rich phase (Aversa and Apicella, 2016).

The formation of the icosahedra phase was dependent on a significant mismatch in atomic size between $\mathrm{Zr}, \mathrm{Cu}$ and $\mathrm{Ni}$ atoms, which are significantly higher than $\mathrm{Be}$ (Saida et al., 2000).

Surface SEM analysis revealed a specific jet channel pattern that is characteristic of flow instability in injection molded parts (Fig. 3).

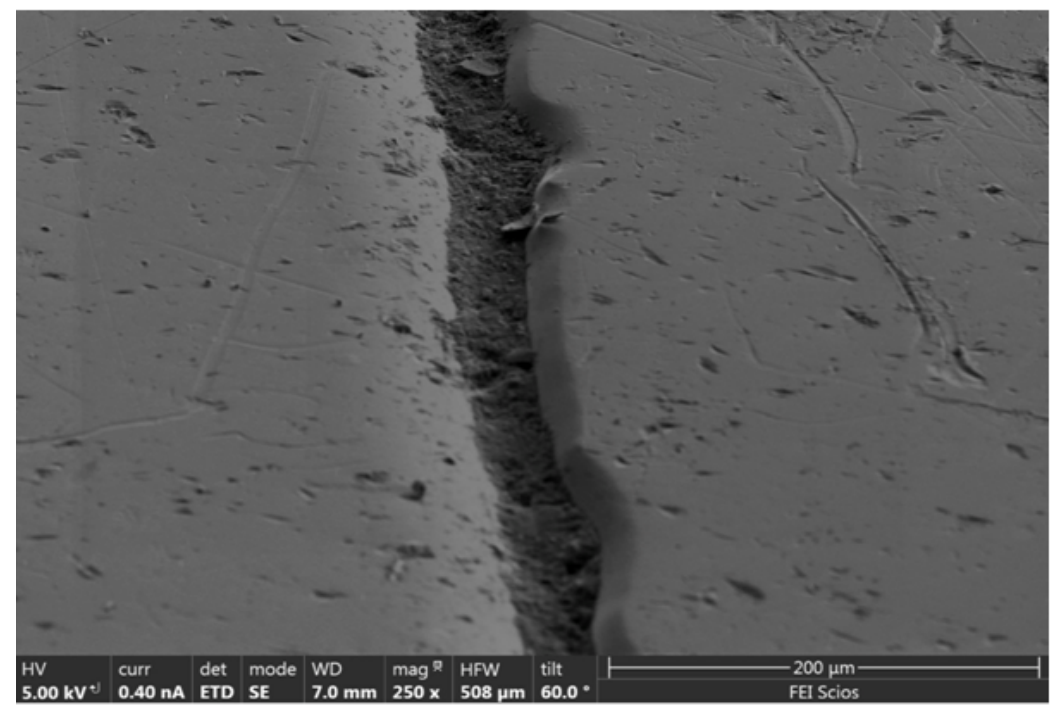

Fig. 3: Groove surface defect on the injection molded BMG slab analyzed using Dual Beam Microscopy

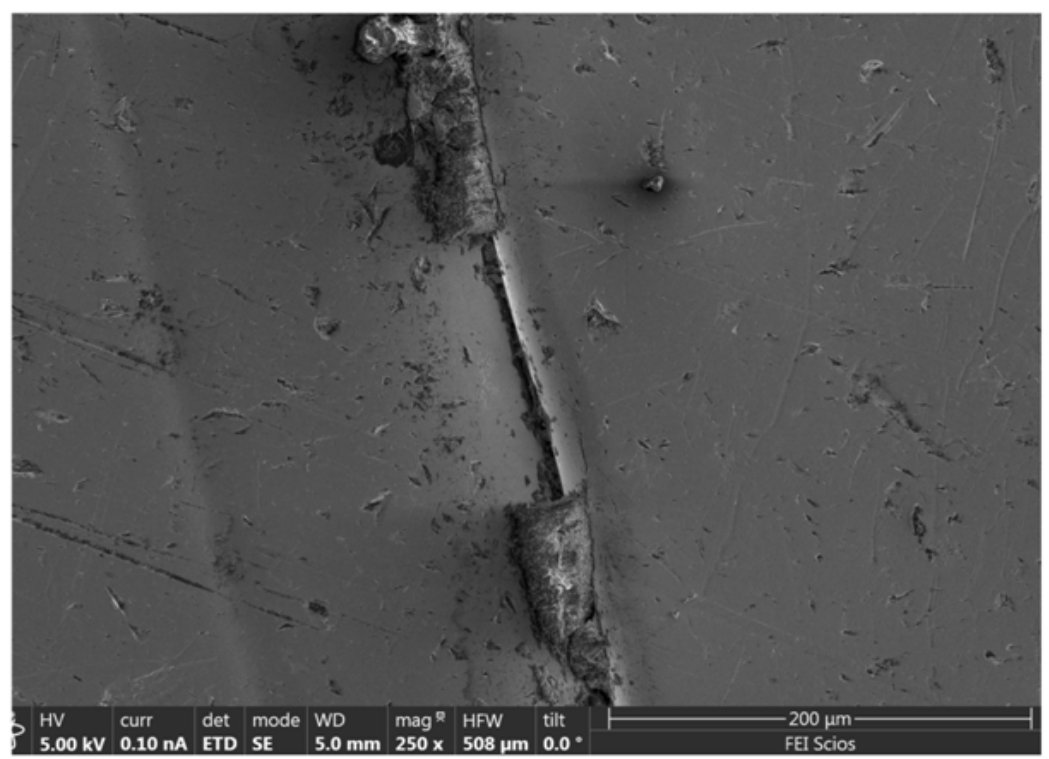

Fig. 4: Water jet debris removal in the surfa 
Similar surface defects in injection molding polymers are observed when the mold is cold and/or the advanced front slows down, resulting in vitrification of the polymer or excessive viscosity growth. In the case of glass injection molding, the reason may be caused by surface defects for the same reasons: A cold mold can generate high temperature gradients in the molten plastic, increasing flux instability and grooves and forming waves. The failure of the groove in Fig. 3 is filled with unknown material. Figure 4 shows a portion of the defect in which the debris was removed.

Analysis of the EDS chemical composition of the filler indicates that the residues were composed of silicates and silicon alumina from the BMG water jet cut. Once removed, the defect morphology (Fig. 4) clearly indicates that the groove derives from the instability of the melt flow.

The main reason for using the microscopic observation method is to be able to examine the ways in which atoms are arranged in molecules and in particular to observe the presence of short-order order clusters and their distribution patterns (Pilarczyk and Podworny, 2015).

By using an ion beam one can allow to investigate both internal morphology in the vicinity of the surface where the vitrification process first occurs and a cross section with a depth of about $60 \mu \mathrm{m}$ that was created using FIB. A platinum deposition that can be seen in (Fig. 5a) was used as a target for Ion Beam in order to spread the material when the beam reaches the surface of the plate.

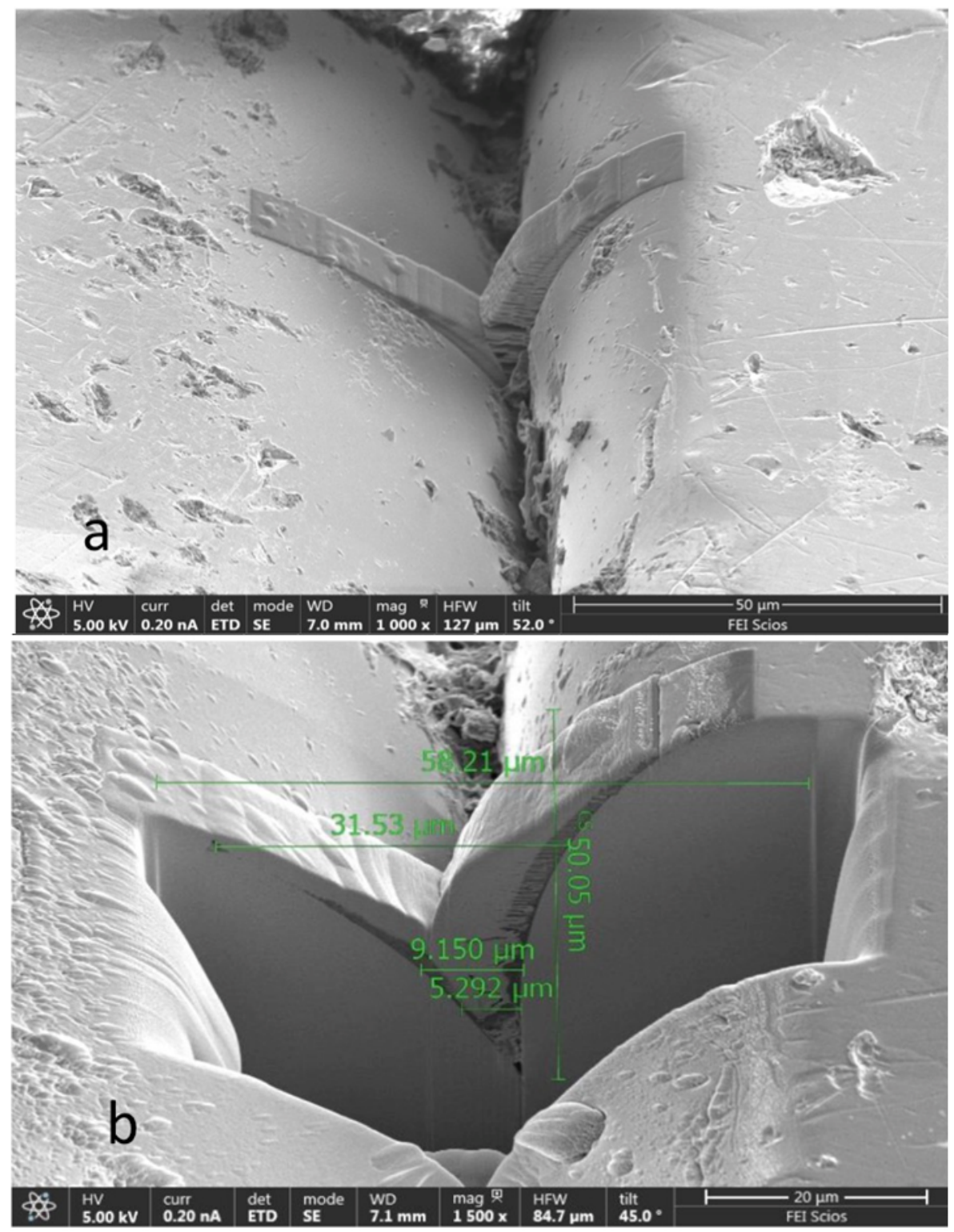

Fig. 5: Cross-section positioning and platinum deposition (a) morphological structure of the defect section (b) 


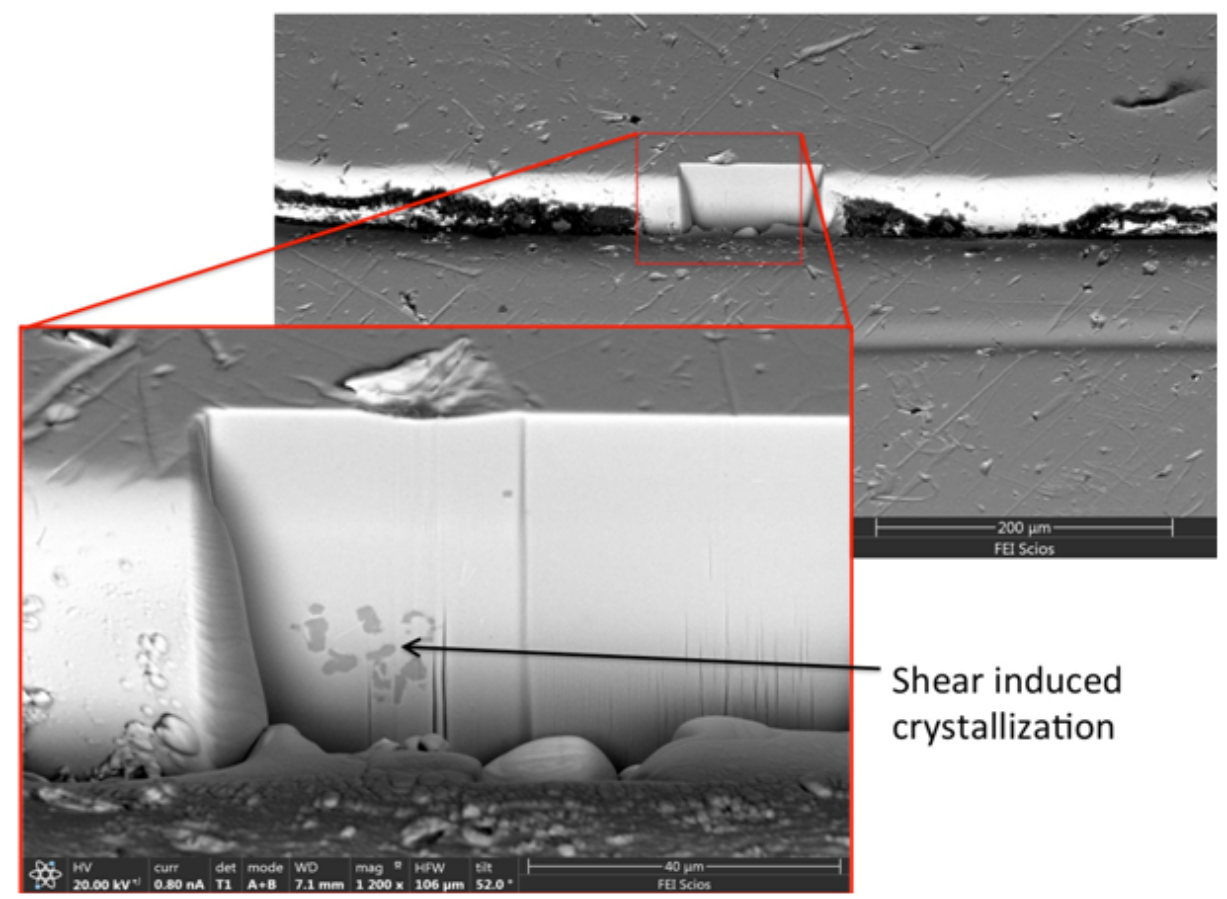

Fig. 6: Frontal view cross-section position in the groove. Detail of shear induced crystalline-phase grains

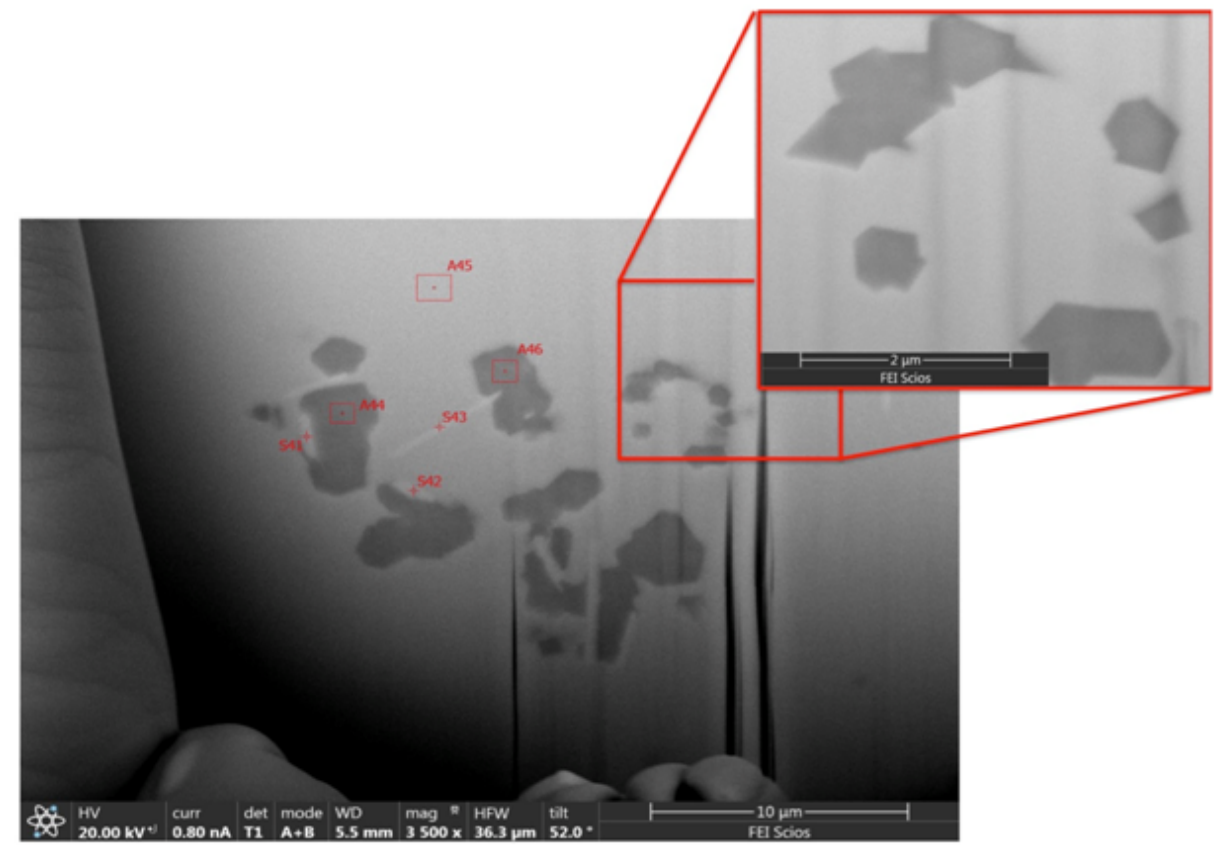

Fig. 7: Details of shear induced crystalline-phase grains

In particular, Fig. 6 shows crystalline-phase grains (black spot in Fig. 6) dispersed with some linear elements (white line in Fig. 6) in a glass phase matrix.

Using EDS, the chemical composition of the selected areas was analyzed. Figure 7 shows the details of the crystallized surface indicating the points that have been analyzed for the atomic composition.
The image of the defective linear defect shows the presence of two types of crystalline inclusions: The needle (white in Fig. 7) and the hexagonal crystals (the top-right figures in Fig. 7). The exact composition can't be determined by EDS because very small atoms such as Be are not detected. EDS analysis was performed on certain areas of the injection molded plate. 
Crystalline inclusions have been described in the literature; Liu et al. (2002) reported that the amount of crystalline inclusions decreases from the center to the outer surface of the plate.

This decrease is probably due to the effects of the cooling rate.

The cooling rate is, in fact, lower in the center than in the outer areas of the sample and this condition increases the formation of a short order and hence of the crystalline granules.

Moreover, in the injected parts, the high shear stresses can be induced by the molten alloy rheology near the die surface, where there is an adjacent solidified glass area, a still fluid but very viscous layer (Fig. 8).

EDS analysis was then limited to $\mathrm{Zr}, \mathrm{Ti}, \mathrm{Cu}$ and $\mathrm{Ni}$ atoms. In particular, the analysis was performed on the amorphous phase (either surface and internal in the vicinity of the surface), as well as on the two types of crystalline inclusions.

These areas are indicated in Fig. 7 as S41, S42 and S43 (white needle crystals), A44 and A46 (dark hexagonal crystals) and A45 (glass amorphous glass).

Subsequent sampling was also carried out in other amorphous parts, such as the inner and outer surfaces of the plate.

\section{Discussion}

The comparative compositional analysis is reported in Table 1.

The composition of the amorphous glass metal is richer in the $\mathrm{Zr}$ atoms $(51.3 \%)$ on the outer surface (where the molten alloy is cooled at the highest speed) while being reduced in the inner layers $(43.8 \%$ at the depth of $20-60$ microns) where, on the contrary, $\mathrm{Ni}$ and $\mathrm{Cu}$ atoms increase their composition from about 15 to $18 \%$ ).

The two types of crystalline inclusions are characterized by significantly different compositions.

Hexagonal crystals are composed of a $\mathrm{Ni}-\mathrm{Cu}$ rich phase (approximately 25\% each) with 37\% $\mathrm{Zr}$ and $12 \% \mathrm{Ti}$.

Needle crystals contain a higher $\mathrm{Zr}$ content than crystal needle (47\% Vs. 37\%) with $\mathrm{Cu}$ and $\mathrm{Ni}$ at $18 \%$ and Ti to $15 \%$.

These compositional differences can be attributed to the thermal and rheological behavior of the melt during injection molding (Geyer et al., 1995; Klement et al., 1960; Lewandowski et al., 2005; Morito and Egami, 1984; Schroers, 2010; Schroers et al., 1999; Syed et al., 2016; Trachenko, 2008).

These shear stresses, such as local crystallization in shear bands formed in heavily deformed BMG (Kanugo et al., 2004), considerably reduce nuclear energy barriers favoring the formation of nano and microcrystalline phases.

In our samples, the subimicron crystal granules are observed in the layer between 20 and 40 microns on the outer surface.

In this interfacial layer (B of Fig. 8), two driving forces act to induce crystal nucleation, the temperature difference greater than the thermodynamic melting temperature (the intermediate layer above the glass transition) and the shorter distance between the crystallisation atoms of the compression and compact atomic alloy in a low volume, layer B of Fig. 8) favors crystalline nucleation and growth.

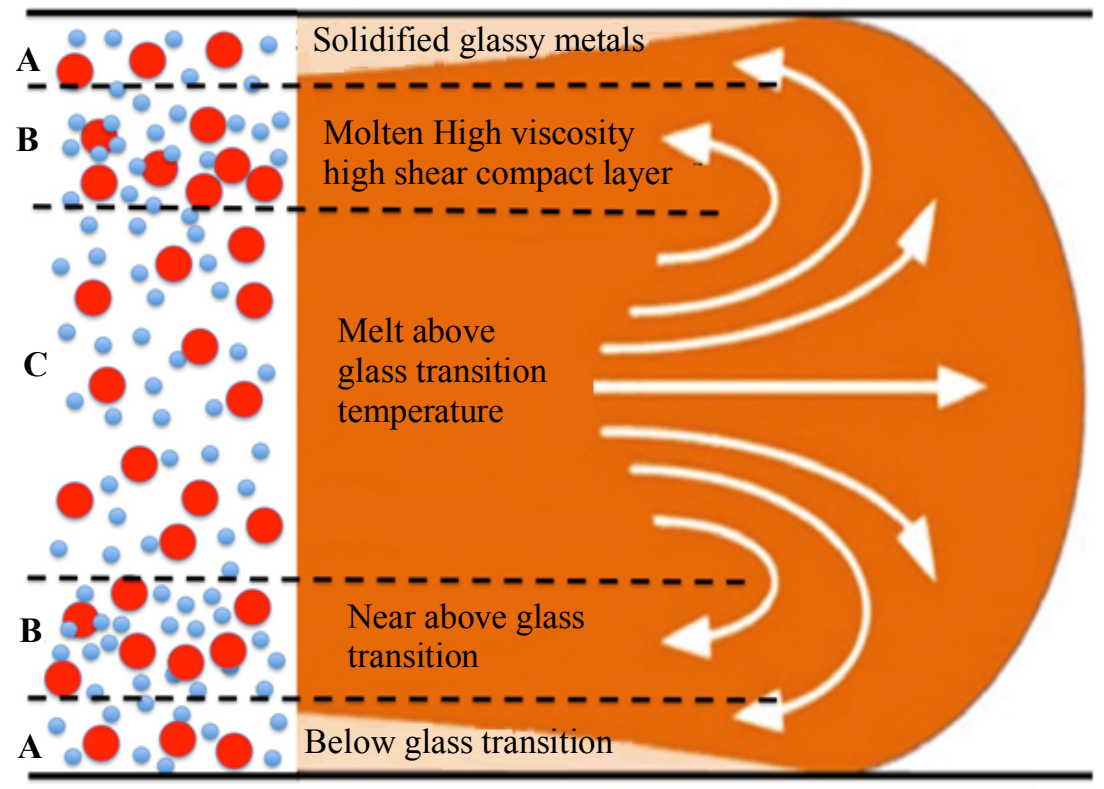

Fig. 8: High Shear stress build up in fountain flow front for injection molding of a BMG 
Raffaella Aversa et al. / International Journal of Structural Glass and Advanced Materials Research 2018, Volume 2: 96.106 DOI: 10.3844/sgamrsp.2018.96.106

Table 1: Compositional EDS analyses of amorphous metal alloy glass and crystalline inclusions

\begin{tabular}{lllll}
\hline Atoms & Amorphous surface & Amorphous internal & Hexagonal crystals & Needle crystals \\
\hline $\mathrm{Zr}$ & $51,3 \pm 2,4$ & $43,8 \pm 2,5$ & $36,8 \pm 2,4$ & $47,2 \pm 2,5$ \\
$\mathrm{Ti}$ & $17,8 \pm 3,8$ & $18,6 \pm 4,7$ & $12,1 \pm 5,6$ & $14,8 \pm 5,4$ \\
$\mathrm{Ni}$ & $15,9 \pm 5,0$ & $18,3 \pm 6,8$ & $24,9 \pm 5,4$ & $19,1 \pm 7,2$ \\
$\mathrm{Cu}$ & $15,0 \pm 5,8$ & $18,8 \pm 8,1$ & $26,1 \pm 6,0$ & $17,1 \pm 8,0$ \\
\hline
\end{tabular}

Following the energy landscape theory (Debenedetti and Stillinger, 2001), inherent structures that are associated with local energy minima are stable stable glass states that are divided by the energy barriers between the various potential equilibrium configurations.

These balanced glass structures can become more compact (in layer B of Fig. 8), redimensioning the atomization into more orderly groups, prone to crystallization (the elastic compression energy is then stored in the crystalline phase).

According to a thermodynamic approach, the excessive energy barrier $\left(\Delta G^{*}\right)$ for the homogeneous nucleus in the amorphous phase in the crystalline phase is (Lee et al., 2006):

$$
\Delta G^{*}=\frac{16}{3} \pi \gamma^{3}\left(\frac{V_{m}^{c}}{\Delta G_{m}+E_{c}+P \Delta V_{m}}\right)
$$

where, $T$ is the temperature, $P$ is the hydrostatic pressure, $\Delta G_{m}$ is the is the molar free energy change in the transformation between the amorphous and crystalline phases, $\gamma$ is the interfacial free energy between the amorphous and crystalline states (to form the critical size crystal nucleus) and $\Delta V_{m}$ is the molar volume change in the transformation between the amorphous $\left(V_{m}^{a}\right)$ and crystalline $\left(V_{m}^{a}\right)$ states, finally, $E_{c}$ is the elastic strain energy induced by the change in volume in the crystallization process (with $E_{c}=\frac{1}{2} E \varepsilon^{2} V_{m}^{c} E_{c}$; with $\mathrm{E}$ the elastic modulus and $\varepsilon=\left(V_{m}^{a}-V_{m}^{c}\right) / 3 V_{m}^{c}$.

According to the previous thermodynamic analysis, the presence of shear stresses increases the compaction of the atoms producing molar volume decreases leading to the reduction of the barrier energy $\Delta G^{*}$.

Equally, the near above temperature of the melt increase the value of the free energy $\Delta G_{m}$ lowering the energy barrier for crystallization.

\section{Conclusion}

The microscopic examination of the internal sections of $\mathrm{Zr}_{44} \mathrm{Ti}_{11} \mathrm{Cu}_{10} \mathrm{Ni}_{10} \mathrm{Be}_{25}$ (LM001B) showed that the sample, characterized by an amorphous structure, also has a short command and can detect crystalline groups with a range of 0.8 to $10 \mu \mathrm{m}$.
The presence, behavior and distribution of crystalline phases for BMG can mainly depend on oxygen impurity, micro-alloying elements and manufacturing process parameters.

The critical value for quaternary and ternary $\mathrm{Zr}$ alloys is $0.4 \%$ (Murty and Hono, 2001). The size range of the icosahedral phase is from 10 to $40 \mathrm{~nm}$, depending on the alloy.

Since GFA (glass capacity) can also be defined as resistance to crystalline phase precipitation, oxygen also has a deleterious effect on it (Eckert et al., 1998; Gebert et al., 1998).

Finally, as shown by the microscopic study, the parameters of the manufacturing process, geometry, size and thickness have a significant effect on the formation of crystalline particles, on their quantity and distribution. In fact, for a more complex part and for manufacturing processes with lower control of the parameters, there are changes in the cooling rate inside the piece, causing different behaviors of crystallization. If the cooling rate is lower, it is easier to find crystalline particles, especially in the intermediate layers between the solidified external glass metal and the liquid still, but melts very hard near its glass transition.

One can now talk about a new material revolution by putting in bulk metallic glasses, Inside Bulk Metallic, (BMGs).

It's about metals that are very different from each other, but they can still be combined with the help of intense heat and melted together to produce a beautifully colored and hot liquid. When this liquid is cooled very quickly (fast enough), the metal atoms manage to retain the liquid in a totally random manner, thus forming an amorphous alloy. Glasses made with this amorphous material are very scratch-resistant, BMG material being a plastic, amorphous, but also elastic, but very resistant. You can even speak one of the most powerful materials known today!

The weight ratio of BMG can usually be twice as high as that of titanium, magnesium or aluminum.

The hardness of the BMG type material is typically a Vickers hardness of more than 500, which is about twice the hardness of most quality stainless steels and titanium and at least four times the hardness of the aluminum and magnesium. 
BMGs can be three times more elastic or more resistant than virtually all known crystal metal alloys.

Some BMGs are highly corrosion-resistant, with alloys containing elements such as beryllium or niobium that tend to be very corrosive. In general, erosion resistance is remarkable in all these BMGs.

The manufacturing of $\mathrm{BMG}$ components requires such plastics, their ability to be processed using a hybrid injection molding and casting mold, casting them resulting in many complicated shapes with high dimensional tolerance and different characteristics.

Thanks to this ease of manufacture, their processing and their surface, they involve very little modification operations. BMGs can also be deformed by forging - such as operations under control atmospheric and temperature.

The paper aims to present studies on the melt flow, melting and rheology of melting in a super-cooled metastable liquid metal, which is injection molded, of the $\mathrm{Zr}_{44}-\mathrm{Ti}_{11}-\mathrm{Cu}_{10}-\mathrm{Ni}_{10}-\mathrm{Be}_{25}$ alloy, which can induce selective crystallization. In this process, high $\mathrm{Be}-$ velocities were observed, $\mathrm{Cu}$ and $\mathrm{Ni}$ atoms that crystallized differently in superficial bulk metallic bulk liquids. We want to highlight and analyze the result of the morphological behavior of microscopic observation regarding Glass Bulk Metallic (BMG) with the composition of a commercial liquid metal alloy (LM001B). One specifies that the injection molded plate was supplied to us by Liquid Metals Technologies Inc., $\mathrm{Ca}$, USA and was manufactured using an Engel injection molding machine operating at $1050-1100^{\circ} \mathrm{C}$. The sample that was observed was then cut with a jet of water. FEI Scios Dual-Beam performed microscopic observation. In a crosssection, the presence of crystalline phases can be observed on short-range command. It is also investigated the presence of short-range command groups, their distribution and the effect they can have on the behaviors and properties of alloys.

\section{Acknowledgement}

The Authors acknowledge Liquid Metals Technologies Inc, Ca USA that kindly supply the samples for the characterization.

\section{Funding Information}

This research has been funded by Italian Ministry of University and Research project FIRB Future in Research 2008 project RBFR08T83J.

\section{Author's Contributions}

This section should state the contributions made by each author in the preparation, development and publication of this manuscript.

\section{Ethics}

Authors should address any ethical issues that may arise after the publication of this manuscript.

\section{References}

Aversa, A. and A. Apicella, 2016. Factors affecting chemo-physical and rheological behaviour of $\mathrm{Zr}_{44-}$ $\mathrm{Ti}_{11}-\mathrm{Cu}_{10}-\mathrm{Ni}_{10}-\mathrm{Be}_{25}$ metal glassy alloy supercooled. Am. J. Eng. Applied Sci., 9: 98-106.

DOI: 10.3844/ajeassp.2016.98.106

Aversa, R., F. Tamburrino, D. Parcesepe and A. Apicella, 2015. Cold crystallization behaviour of a commercial $\mathrm{Zr}_{44}-\mathrm{Ti}_{11}-\mathrm{Cu}_{10}-\mathrm{Ni}_{10}-\mathrm{Be}_{25}$ metal glassy alloy. Adv. Mater. Res., 1088: 206-212.

DOI: 10.4028/www.scientific.net/AMR.1088.206

Aversa, R., R.V.V. Petrescu, A. Apicella and F.I.T. Petrescu, 2017a. Nano-diamond hybrid materials for structural biomedical application. Am. J. Biochem. Biotechnol., 13: 34-41. DOI: 10.3844/ajbbsp.2017.34.41

Aversa, R., R.V. Petrescu, B. Akash, R.B. Bucinell and J.M. Corchado et al., 2017b. Kinematics and forces to a new model forging manipulator. Am. J. Applied Sci., 14: 60-80. DOI: 10.3844/ajassp.2017.60.80

Aversa, R., R.V. Petrescu, A. Apicella, I.T.F. Petrescu and J.K. Calautit et al., 2017c. Something about the $\mathrm{V}$ engines design. Am. J. Applied Sci., 14: 34-52. DOI: 10.3844/ajassp.2017.34.52

Aversa, R., D. Parcesepe, R.V.V. Petrescu, F. Berto and G. Chen et al., 2017d. Process ability of bulk metallic glasses. Am. J. Applied Sci., 14: 294-301. DOI: 10.3844/ajassp.2017.294.301

Aversa, R., R.V.V. Petrescu, B. Akash, R.B. Bucinell and J.M. Corchado et al., 2017e. Something about the balancing of thermal motors. Am. J. Eng. Applied Sci., 10: 200-217.

DOI: 10.3844/ajeassp.2017.200.217

Aversa, R., F.I.T. Petrescu, R.V. Petrescu and A. Apicella, 2016a. Biomimetic FEA bone modeling for customized hybrid biological prostheses development. Am. J. Applied Sci., 13: 1060-1067. DOI: 10.3844/ajassp.2016.1060.1067

Aversa, R., D. Parcesepe, R.V. Petrescu, G. Chen and F.I.T. Petrescu et al., 2016b. Glassy amorphous metal injection molded induced morphological defects. Am. J. Applied Sci., 13: 1476-1482.

DOI: 10.3844/ajassp.2016.1476.1482

Aversa, R., R.V. Petrescu, F.I.T. Petrescu and A. Apicella, 2016c. Smart-factory: Optimization and process control of composite centrifuged pipes. Am. J. Applied Sci., 13: 1330-1341. DOI: 10.3844/ajassp.2016.1330.1341 
Aversa, R., F. Tamburrino, R.V. Petrescu, F.I.T. Petrescu and M. Artur et al., 2016d. Biomechanically inspired shape memory effect machines driven by muscle like acting NiTi alloys. Am. J. Applied Sci., 13: 1264-1271.

DOI: 10.3844/ajassp.2016.1264.1271

Aversa, R., E.M. Buzea, R.V. Petrescu, A. Apicella and M. Neacsa et al., 2016e. Present a mechatronic system having able to determine the concentration of carotenoids. Am. J. Eng. Applied Sci., 9: 1106-1111. DOI: 10.3844/ajeassp.2016.1106.1111

Aversa, R., R.V. Petrescu, R. Sorrentino, F.I.T. Petrescu and A. Apicella, 2016f. Hybrid ceramo-polymeric nanocomposite for biomimetic scaffolds design and preparation. Am. J. Eng. Applied Sci., 9: 1096-1105. DOI: 10.3844/ajeassp.2016.1096.1105

Aversa, R., V. Perrotta, R.V. Petrescu, C. Misiano and F.I.T. Petrescu et al., 2016g. From structural colors to super-hydrophobicity and achromatic transparent protective coatings: Ion plating plasma assisted $\mathrm{TiO}_{2}$ and $\mathrm{SiO}_{2}$ Nano-film deposition. Am. J. Eng. Applied Sci., 9: 1037-1045.

DOI: 10.3844/ajeassp.2016.1037.1045

Aversa, R., R.V. Petrescu, F.I.T. Petrescu and A. Apicella, 2016h. Biomimetic and evolutionary design driven innovation in sustainable products development. Am. J. Eng. Applied Sci., 9: 1027-1036. DOI: 10.3844/ajeassp.2016.1027.1036

Aversa, R., R.V. Petrescu, A. Apicella and F.I.T. Petrescu, 2016i. Mitochondria are naturally micro robots-a review. Am. J. Eng. Applied Sci., 9: 991-1002. DOI: 10.3844/ajeassp.2016.991.1002

Aversa, R., R.V. Petrescu, A. Apicella and F.I.T. Petrescu, 2016j. We are addicted to vitamins $\mathrm{C}$ and E-A review. Am. J. Eng. Applied Sci., 9: 1003-1018.

DOI: 10.3844/ajeassp.2016.1003.1018

Aversa, R., R.V. Petrescu, A. Apicella and F.I.T. Petrescu, 2016k. Physiologic human fluids and swelling behavior of hydrophilic biocompatible hybrid ceramo-polymeric materials. Am. J. Eng. Applied Sci., 9: 962-972.

DOI: 10.3844/ajeassp.2016.962.972

Aversa, R., R.V. Petrescu, A. Apicella and F.I.T. Petrescu, 20161. One can slow down the aging through antioxidants. Am. J. Eng. Applied Sci., 9: 1112-1126. DOI: 10.3844/ajeassp.2016.1112.1126

Aversa, R., R.V. Petrescu, A. Apicella and F.I.T. Petrescu, 2016m. About homeopathy or «Similia similibus curentur $\gg$. Am. J. Eng. Applied Sci., 9: 1164-1172. DOI: 10.3844/ajeassp.2016.1164.1172

Aversa, R., R.V. Petrescu, A. Apicella and F.I.T. Petrescu, 2016n. The basic elements of life's. Am. J. Eng. Applied Sci., 9: 1189-1197.

DOI: 10.3844/ajeassp.2016.1189.1197

Aversa, R., F.I.T. Petrescu, R.V. Petrescu and A. Apicella, 2016o. Flexible stem trabecular prostheses. Am. J. Eng. Applied Sci., 9: 1213-1221. DOI: 10.3844 /ajeassp.2016.1213.1221
Busch, R., 2000. The thermophysical properties of bulk metallic glass-forming liquids. JOM, 52: 39-42. DOI: $10.1007 / \mathrm{s} 11837-000-0160-7$

Debenedetti, P.G. and F.H. Stillinger, 2001. Supercooled liquids and the glass transition. Nature, 410: 259-267. DOI: $10.1038 / 35065704$

Eckert, J., N. Mattern, M. Zinkevitch and M. Seidel, 1998. Crystallization behavior and phase formation in $\mathrm{Zr}-\mathrm{Al}-\mathrm{Cu}-\mathrm{Ni}$ metallic glass containing oxygen. Mater. Trans., 39: 623-632.

DOI: 10.2320/matertrans 1989.39.623

Gebert, A., J. Eckert and L. Schultz, 1998. Effect of oxygen on phase formation and thermal stability of slowly cooled $\mathrm{Zr}_{65} \mathrm{Al}_{7.5} \mathrm{Cu}_{7.5} \mathrm{Ni}_{10}$ metallic glass. Acta Mater., 46: 5475-5482.

DOI: 10.1016/S1359-6454(98)00187-6

Geyer, U., S. Schneider, W.L. Johnson, Y. Qiu and T.A. Tombrello et al., 1995. Small atom diffusion and breakdown of the Stokes-Einstein relation in the supercooled liquid state of the $\mathrm{Zr}_{46.7} \mathrm{Ti}_{8.3} \mathrm{Cu}_{7.5} \mathrm{Ni}_{10} \mathrm{Be}_{27.5}$ alloy. Phys. Rev. Lett., 75: 2364-2364. DOI: 10.1103/PhysRevLett.75.2364

Huang, Y., P. Xue, S. Guo, Y. Wu and X. Cheng et al., 2016. Liquid-solid joining of bulk metallic glasses. Scientific Rep., 6: 30674-30674. DOI: $10.1038 /$ srep30674

Klement, W., R.H. Willens and P. Duwez, 1960. Noncrystalline structure in solidified gold-silicon alloys. Nature, 187: 869-869. DOI: 10.1038/187869b0

Kanugo, B.P., S.C. Gladeb, P. Asoka-Kumarb and K.M. Floresa, 2004. Characterization of free volume changes associated with shear band formation in $\mathrm{Zr}$ and $\mathrm{Cu}$-based bulk metallic glasses. Intermetallics, 12: $1073-1080$.

DOI: $10.1016 /$ j.intermet.2004.04.033

Lee, S.W., M.Y. Huh, E. Feury and J.C. Lee, 2006. Crystallization-induced plasticity of $\mathrm{Cu}-\mathrm{Zr}$ containing bulk amorphous alloys. Acta Mater., 54: 349-355. DOI: 10.1016/j.actamat.2005.09.007

Lewandowski, J.J., W.H. Wang and A.L. Greer, 2005. Intrinsic plasticity or brittleness of metallic glasses. Philos Magaz. Lett., 85: 77-87. DOI: 10.1080/09500830500080474

Liu, C.T., M.F. Chisholm and M.K. Miller, 2002. Oxygen impurity and microalloying effect in a $\mathrm{Zr}$ based bulk metallic glass alloy. Intermetallics, 10: 1105-1112. DOI: 10.1016/S0966-9795(02)00131-0

Mirsayar, M.M., V.A. Joneidi, R.V.V. Petrescu, F.I.T. Petrescu and F. Berto, 2017. Extended MTSN criterion for fracture analysis of soda lime glass. Eng. Fracture Mechan., 178: 50-59.

DOI: 10.1016/j.engfracmech.2017.04.018 
Morito, N. and T. Egami, 1984. Internal friction and reversible structural relaxation in the metallic glass $\mathrm{Fe}_{32} \mathrm{Ni}_{36} \mathrm{Cr}_{14} \mathrm{P}_{12} \mathrm{~B}_{6}$. Acta Metall., 32: 603-613. DOI: $10.1016 / 0001-6160(84) 90071-3$

Murty, B.S. and K. Hono, 2001. Nano-quasicrystallization of $\mathrm{Zr}$ based metallic glasses. Mater. Sci. Eng., 312: 253-261. DOI: 10.1016/S0921-5093(00)01861-X

Petrescu, F.I. and J.K. Calautit, 2016a. About the light dimensions. Am. J. Applied Sci., 13: 321-325.

DOI: 10.3844/ajassp.2016.321.325

Petrescu, F.I. and J.K. Calautit, 2016b. About nano fusion and dynamic fusion. Am. J. Applied Sci., 13: 261-266. DOI: 10.3844/ajassp.2016.261.266

Petrescu, F.I., A. Apicella, R. Aversa, R.V. Petrescu and J.K. Calautit et al., 2016a. Something about the mechanical moment of inertia. Am. J. Applied Sci., 13: 1085-1090.

DOI: 10.3844 /ajassp.2016.1085.1090

Petrescu, F.I., A. Apicella, R.V. Petrescu, S. Kozaitis and R. Bucinell et al., 2016b. Environmental protection through nuclear energy. Am. J. Applied Sci., 13: 941-946.

DOI: 10.3844/ajassp.2016.941.946

Petrescu, R.V., R. Aversa, A. Apicella, S. Li and G. Chen et al., 2016c. Something about electron dimension. Am. J. Applied Sci., 13: 1272-1276. DOI: 10.3844 /ajassp.2016.1272.1276

Petrescu, R.V., R. Aversa, A. Apicella, F. Berto and S. Li et al., 2016d. Ecosphere protection through green energy. Am. J. Applied Sci., 13: 1027-1032. DOI: 10.3844/ajassp.2016.1027.1032

Petrescu, F.1., E. Buzea, L. Nănuţ, M. Neacşa and C. Nan, 2015. The role of antioxidants in slowing aging of skin in a human. Anal. Craiova Univ., 20: $567-574$
Petrescu, R.V., R. Aversa, A. Apicella and F.I. Petrescu, 2016e. Future medicine services robotics. Am. J. Eng. Applied Sci., 9: 1062-1087. DOI: 10.3844/ajeassp.2016.1062.1087

Pilarczyk, W. and J. Podworny, 2015. Study of Atoms arrangment in Zr-Based Bulk Metallic Glass Structure. Acta Phys. Polonica A, 129: 216-218. DOI: 10.12693/APhysPolA.129.216

Schroers, J., 2010. Processing of bulk metallic glass. Adv. Mater., 22: 1566-1597.

DOI: 10.1002 /adma.200902776

Schroers, J., A Masuhr, W.L. Johnson and R. Busch, 1999. Pronounced asymmetry in the crystallization behavior during constant heating and cooling of a bulk metallic glass-forming liquid. Phys. Rev. B, 60: 11855-11858. DOI: 10.1103/PhysRevB.60.11855

Saida, J., M. Matsushita and A. Inoue, 2000. Formation of an Icosahedral Quasicrystalline Phase in $\mathrm{Zr}_{65} \mathrm{Al}_{7.5} \mathrm{Ni}_{10} \mathrm{M}_{17.5}(\mathrm{M}=\mathrm{Pd}$, Au or Pt) Alloys. Mater. Trans. JIM, 41: 362-365.

DOI: 10.2320/matertrans 1989.41.362

Syed, J., N. Sahar, R. Aversa, R.V.V. Petrescu and D. Apicella et al., 2016. Periodontal bone substitutes application techniques and cost evaluation: A review. Am. J. Eng. Applied Sci., 9: 951-961.

DOI: 10.3844/ajeassp.2016.951.961

Trachenko, K., 2008. The Vogel-Fulcher-Tammann law in the elastic theory of glass transition. J. NonCrystalline Solids, 354: 3903-3906. DOI: 10.1016/j.jnoncrysol.2008.05.021 